\title{
An Analysis of Background Factors Influencing Selection of Residency Facility for Dental Students in Universities Located in Rural Areas in Japan
}

\author{
H. Kono ${ }^{1, *}$, H. Sasahara ${ }^{2}$, S. Furukawa ${ }^{1}$ and N. Taguchi ${ }^{1}$ \\ ${ }^{I}$ Department of Dental Education, Kagoshima University Graduate School of Medical and Dental Sciences, Kagoshima, \\ Japan; ${ }^{2}$ Department of Integrated Health Sciences, Hiroshima University Institute of Biomedical and Health Sciences, \\ Hiroshima, Japan
}

\begin{abstract}
Background: In Japan, since 2006, participation in a 1-year residency programme by all dentists who have passed the National Board Dental Examination has been mandatory. Therefore, a 'matching system' has become necessary for dental students in their final year to decide their desired residency facility, but the rate of matching in dental schools located in rural areas is still low. Aim: The principal aim of this study was to elucidate the background factors influencing the selection of residency facilities by dental students in rural areas to facilitate the training of dentists working in local communities. Methods: Using the matching results from 554 final-year students of Kagoshima University Faculty of Dentistry from 2005 to 2013, multiple logistic regression analysis was performed on the background factors of the subjects. Results: Concerning the selection of the residency facility, it was verified that there were strong background factors for subjects to select residency facilities in their hometown, but compared with subjects from other regions, those from Kinki and Kanto regions did not select residency facilities in their hometown. Compared with males, a significantly higher number of females selected residency facilities in their hometown. A significantly higher number of subjects who repeated a school year selected the residency facility of their alma mater. Conclusion: In dental schools of national universities located in provinces, the establishment of a quota system for students from the region, where possible, is one of the most effective steps for securing future dental trainees.
\end{abstract}

Keywords: Dental students, matching programme, residency, rural area.

\section{INTRODUCTION}

Since 2006, it has been mandatory for graduates from Japanese dental schools who have passed the National Board Dental Examination to participate in 1-year postgraduate training $[1,2]$. Therefore, it has become necessary for finalyear students in dental schools to select a postgraduate residency facility before taking the national examination. This selection is based on a programme using the Gale-Shapley stable matching algorithm [3] provided by the Japan Dental Residency Matching Programme (hereinafter referred to as 'matching programme').

In the field of medicine, a 2-year residency programme has been mandatory since 2004, and the selection of residency facilities was made through the same matching system as that used for dentistry $[4,5]$. However, it was pointed out that this new residency system led to the acceleration of a shortage in the number of doctors in rural areas [6]. Furthermore, it was reported that doctors who underwent residency training in urban areas often continued to work in urban areas after completing their residency training [6]. Thus, examining the region where doctors undergo postgraduate training is important for evaluating the geographic distribution of doctors.

*Address correspondence to this author at the Department of Dental Education, Kagoshima University Graduate School of Medical and Dental Sciences, 8-35-1 Sakuragaoka, Kagoshima 890-8544 Japan; Tel: +81-99-2756049; Fax: +81-99275-6049; E-mail: hiro164@ dent.kagoshima-u.ac.jp
In contrast, in the field of dentistry, the problem of community healthcare has been overshadowed by the problem of a surplus of dentists, and the field of dentistry has not attracted public attention compared with the field of medicine $[7,8]$. The field of dentistry differs from the field of medicine, except for university hospitals, given that there are few residency facilities designated by the Ministry of Health, Labour and Welfare (MHLW), and the results of the matching programme show that the matching rate for university hospitals is higher compared with the rate in the field of medicine $[9,10]$. However, after the start of the new dental residency programme, the matching rate for university hospitals in rural areas has continued to be low compared with that for university hospitals in urban areas [10]. Similar to doctors, the geographic distribution of dentists in rural areas has become a potential problem. Outside Japan, it has been reported that in countries such as Australia, there is a shortage in the number of dentists in rural and remote areas [1113]. In the United States, the majority of the population has sufficient dental care, but residents in remote areas still experience the problem of limited access to dental care [14, 15]. Furthermore, in Canada, it was reported that the proportion of dentists in rural areas was $11 \%$ compared with $21 \%$ of the general population in the same areas [16]. Thus, many examples showing the problem of inequalities in access to dental care in urban and rural areas have been identified. Ensuring not only efficiency but also fairness is important for access to healthcare in rural and remote areas. Even if there is no issue with the ratio of dentists to the general population, 
the overall number of dentists in rural and remote areas is insufficient due to the extended distance from the area of the residents to the clinics. In Japan, dental care is covered by National Health Insurance [17], and in the majority of the cases, dental care is supported by this public assistance. Therefore, to ensure fairness and a system that allows any citizen to receive care and 'equal treatment based on the latest standards anytime and anywhere', it is critical to promote the training of dentists who will support healthcare in local communities. With the emergence of the issue of a superaging society, the promotion of programmes such as home healthcare by the MHLW in Japan has increased the importance of establishing a foundation for local community healthcare, and the supply and geographic distribution of dentists in rural areas have become critical policy issues in the field of social dentistry [17].

Therefore, the principal aim of this study was to elucidate background factors influencing the selection of residency facilities by dental students to construct a practical training platform for dentists who will support healthcare in local communities. A detailed analysis of background factors influencing the selection of residency facilities by dental students will contribute to attracting dental trainees and students who wish to work in regional universities located in provinces as well as contribute to the development of human resources who will support healthcare in local communities in the future.

\section{MATERIALS AND METHODS}

We used data from the 9-year period from 2005 to 2013 based on the list of students held by the Educational Affairs Section of Kagoshima University Faculty of Dentistry and the list of matching programme results of the Residency Unit of the General Affairs Section of Kagoshima University Medical and Dental Hospital (total number of students, 554; males, 361; females, 193). Items analysed were as follows: gender, age, year of graduation, repeating a school year, failing the national examination, hometown and prefecture where the residency facility was located. Based on these items, multiple logistic regression analysis was performed on students who selected their alma mater for their residency facility, those who selected a facility in their hometown and those who selected a facility in an urban location (i.e. more urban than the area of their alma mater or their hometown). All statistical analyses were performed using the PASW v.21 statistical package (IBM SPSS Statistics, IBM Corporation, Chicago, IL, USA), and statistical significance was set at $\mathrm{p}<0.05$.

Ethical considerations were addressed using data from anonymous records, which cannot be linked to individuals; no data contained personally identifiable information. Furthermore, the present study was part of a study approved by the Ethics Committee for Epidemiological Studies of Kagoshima University Graduate School of Medical and Dental Sciences (Approval No. 375).

\section{RESULTS}

Students' characteristics and the proportion of students selecting the residency facility at Kagoshima University for their respective specialities are shown in Table 1. The male: female ratio was approximately $2: 1$. The age of the largest group was
25 years, followed by a group with the age of 26 years, with the third largest group being in the age group of 30-34 years. It is required that students should reach the minimum age of 24 years before their final year for admission into graduate school; the proportion of these students was $11.2 \%$. The proportion of students who repeated a school year before graduation was $25.8 \%$, implying that approximately one of four students had repeated a school year. The number of students who failed the national examination and participated in the repeated matching programme was $11.7 \%$. Regarding the hometown of students, the number of students from Kagoshima Prefecture, where Kagoshima University is located, was the greatest at $25.8 \%$, followed by $25.1 \%$ being the number of students from the Kyushu region, excluding Kagoshima; the majority of students were from the Kyushu region (the region to which Kagoshima Prefecture belongs). The proportion of students from prefectural capitals with populations smaller and greater than the population of Kagoshima City was $34.7 \%$ and $39.4 \%$, respectively.

The results of the multiple logistic regression analysis of the relationship between the selection of the alma mater for their residency facility and background factors are shown in Table 2. An association between the selection of the residency facility and the items concerning repeating a school year and having Kagoshima as their hometown (the location of the alma mater) was observed; particularly, the association with having Kagoshima as their hometown was strong. In contrast, no gender differences were noted. Furthermore, no significant association with age was noted on the basis of 24year-old students who had neither failed the entrance examination nor repeated a school year. No significant differences were noted in any year when compared with the start of the matching programme in 2005.

The results of the multiple logistic regression analysis of the association with the selection of the residency facility in the hometown of students are shown in Table 3. It was noted that, compared with males, females more often selected a residency facility in their hometown. No association was observed for age, year of graduation or failing the national examination. When the Kyushu region, except for Kagoshima, was used as the point of reference, it was shown that students from Kinki and Kanto regions did not select residency facilities in their hometown.

The multiple logistic regression analysis of the association with the selection of residency facilities in urban areas was performed. The results relating to whether students selected facilities located in prefectures within prefectural capitals that had populations greater than the population of $\mathrm{Ka}$ goshima City are shown in Table 4 . No significant relationship was observed for gender, age, year of graduation, repeating a school year, failing the national examination or hometown. The results relating to whether students selected facilities located in prefectures within prefectural capitals that had greater populations than the population of the prefectural capital of their hometown are shown in Table 5. Similar to the case of Table 4, no significant relationship was observed for gender, age, year of graduation, repeating a school year or failing the national examination. However, a preference for urban areas was observed for those from Shikoku, Kinki, Kanto, Tohoku and Hokkaido regions. 
Table 1. Characteristics of final year students in Kagoshima University Faculty of Dentistry from 2005 to 2013.

\begin{tabular}{|c|c|c|c|c|c|c|}
\hline Variables & & Number & $\%$ & $\begin{array}{l}\text { Number of matched } \\
\text { Kagoshima Univ. }\end{array}$ & $\%$ & $\chi^{2}$-test \\
\hline \multirow{2}{*}{ Gender } & Male & 361 & 65.2 & 187 & 51.8 & \\
\hline & Female & 193 & 34.8 & 80 & 41.5 & $0.020 *$ \\
\hline \multirow{9}{*}{ Age } & 24 & 62 & 11.2 & 28 & 45.2 & \\
\hline & 25 & 140 & 25.3 & 52 & 37.1 & \\
\hline & 26 & 99 & 17.9 & 41 & 41.4 & \\
\hline & 27 & 54 & 9.7 & 24 & 44.4 & \\
\hline & 28 & 41 & 7.4 & 22 & 53.7 & \\
\hline & 29 & 30 & 5.4 & 20 & 66.7 & \\
\hline & $30 \sim 34$ & 84 & 15.2 & 53 & 63.1 & \\
\hline & $35 \sim 39$ & 22 & 4.0 & 13 & 59.1 & \\
\hline & $40 \sim 69$ & 22 & 4.0 & 14 & 63.6 & $0.002 * *$ \\
\hline \multirow{9}{*}{ Year of graduation } & 2005 & 75 & 13.5 & 38 & 50.7 & \\
\hline & 2006 & 72 & 13.0 & 41 & 56.9 & \\
\hline & 2007 & 64 & 11.6 & 32 & 50.0 & \\
\hline & 2008 & 61 & 11.0 & 24 & 39.3 & \\
\hline & 2009 & 56 & 10.1 & 22 & 39.3 & \\
\hline & 2010 & 57 & 10.3 & 30 & 52.6 & \\
\hline & 2011 & 55 & 9.9 & 32 & 58.2 & \\
\hline & 2012 & 60 & 10.8 & 24 & 40.0 & \\
\hline & 2013 & 54 & 9.7 & 24 & 44.4 & 0.217 \\
\hline \multirow{2}{*}{ Repeat year } & No & 411 & 74.2 & 175 & 42.6 & \\
\hline & Yes & 143 & 25.8 & 92 & 64.3 & $0.000 * * *$ \\
\hline \multirow{2}{*}{ Fail the National Exam. } & No & 489 & 88.3 & 230 & 47.0 & \\
\hline & Yes & 65 & 11.7 & 37 & 56.9 & 0.134 \\
\hline \multirow{8}{*}{ Hometown } & Kagoshima prefecture & 143 & 25.8 & 107 & 74.8 & \\
\hline & Kyushu region (except Kagoshima) & 139 & 25.1 & 61 & 43.9 & \\
\hline & Shikoku region & 31 & 5.6 & 10 & 32.3 & \\
\hline & Chugoku region & 29 & 5.2 & 8 & 27.6 & \\
\hline & Kinki region & 80 & 14.4 & 36 & 45.0 & \\
\hline & Chubu region & 56 & 10.1 & 18 & 32.1 & \\
\hline & Kanto region & 60 & 10.8 & 24 & 40.0 & \\
\hline & $\begin{array}{c}\text { Tohoku region, Hokkaido region, } \\
\text { Overseas }\end{array}$ & 16 & 2.9 & 3 & 18.8 & $0.000 * * *$ \\
\hline \multirow{4}{*}{$\begin{array}{l}\text { Population of prefectural } \\
\text { capital }\end{array}$} & $<$ Kagoshima City & 192 & 34.7 & 80 & 41.7 & \\
\hline & $>$ Kagoshima City & 218 & 39.4 & 80 & 36.7 & 0.303 \\
\hline & (Kagoshima City) & (143) & $(25.8)$ & (107) & (74.8) & \\
\hline & (Overseas) & (1) & $(0.0)$ & (0) & $(0.0)$ & \\
\hline Total & & 554 & 100.0 & 267 & 48.2 & \\
\hline
\end{tabular}


Table 2. Multiple logistic regression analysis of characteristics associated with selection of Kagoshima University.

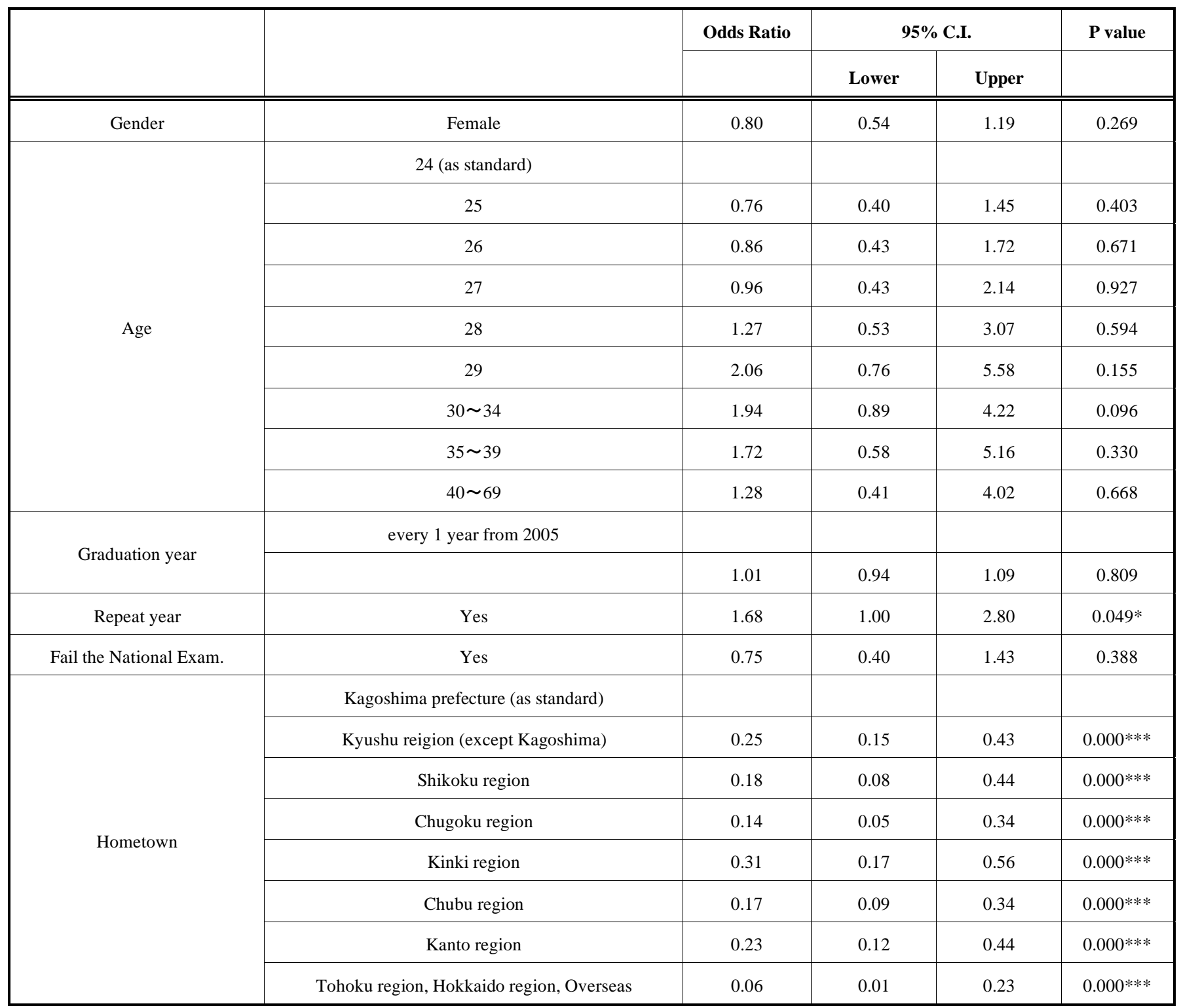

$*: \mathrm{p}<0.05, * * *: \mathrm{p}<0.001$

\section{DISCUSSION}

A significant relationship was observed between selecting the alma mater for their residency facility and having Kagoshima Prefecture as their hometown (hereinafter referred to as 'prefectural students'). Concerning the selection of Kagoshima University by prefectural students, the factors of alma mater and hometown were noted. First, an examination of alma mater was performed. There are 11 national university dental schools in Japan, and eight of these are located in cities designated by government ordinance (those with a population of 700,000 or more, hereinafter referred to as 'urban areas'), and three are located in provincial cities (hereinafter referred to as 'provincial areas'), including Kagoshima University (Fig. 1). Japan is divided into eight regions: Hokkaido, Tohoku, Kanto, Chubu, Kinki, Chugoku, Shikoku and Kyushu/Okinawa. One national university dental school is located in each of the regions of Hokkaido, To- hoku, Kanto, Chubu, Kinki and Shikoku, two are located in the Chugoku region and three in the Kyushu/Okinawa region [9]. The mean matching of students from the same school in national universities from 2005 to 2013 (the ratio of students from the same school for the matching quota) was $64.2 \%$; the mean of those from urban areas was $62.2 \%$, and the mean of those from provincial areas was $71.4 \%$ [9]. The mean rate was $74.2 \%$ for students from Kagoshima University, showing the same trend as the mean of those from provincial areas. It has been reported that dental students prefer to pursue their education in the area in which they live [18]; similarly, in Japan, the rate of students who selected their alma mater was high. However, the reason why the same school ratio was higher for provincial areas compared with that for urban areas was that the quotas for matching were not met in provincial facilities compared with those met in urban facilities [9]; it appears that the same school ratio was higher. Concerning department quotas, the proportion of 
Table 3. Multiple logistic regression analysis of background factors associated with selection of hometown.

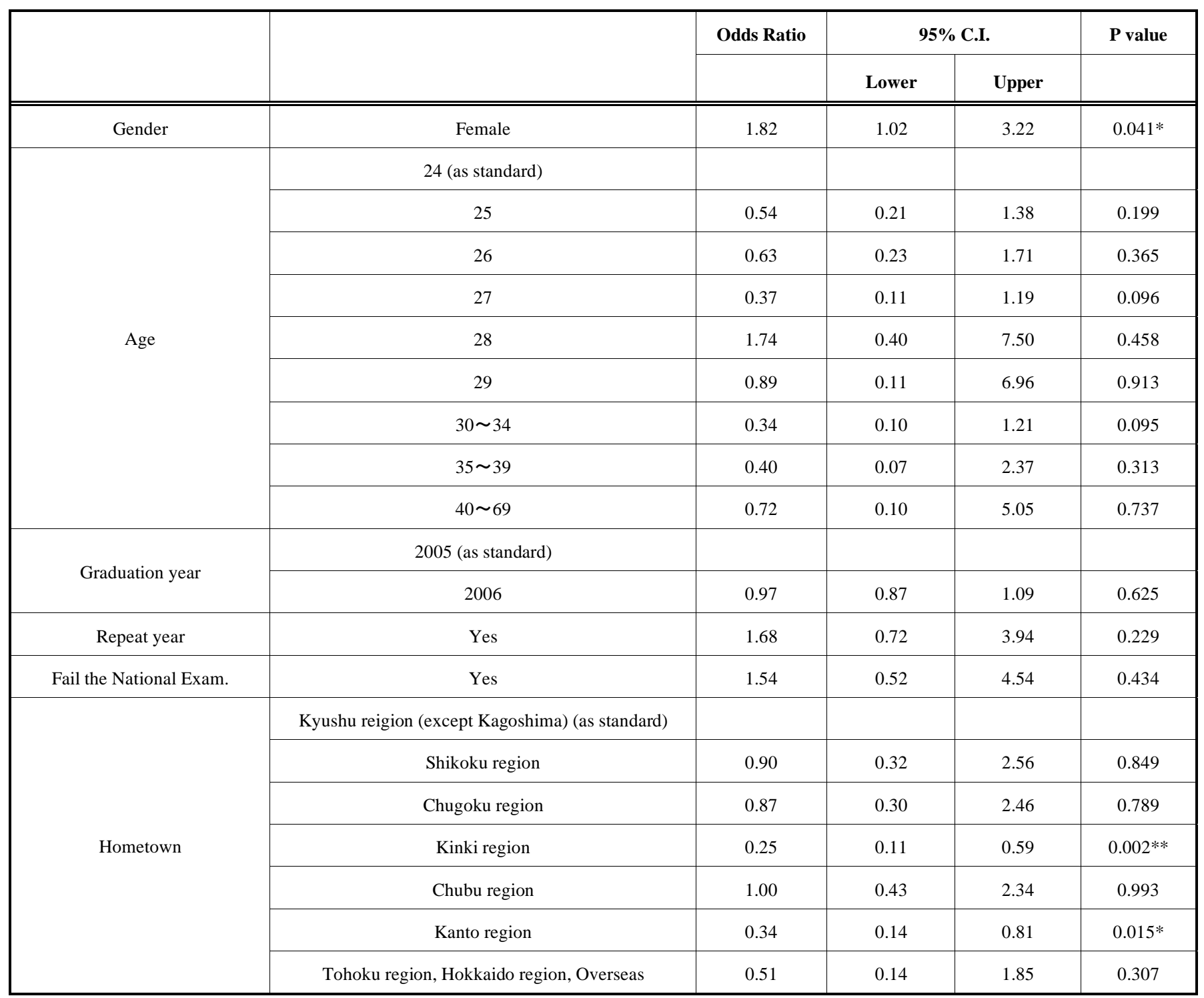

$*: \mathrm{p}<0.05, * *: \mathrm{p}<0.01$

students who selected their own school for the residency facility, for example, in 2011 was $77.6 \%$ (319/411) in urban areas and $71.3 \%(102 / 143)$ in rural areas [9]. This is probably due to the combined factors of alma mater and the preference for urban areas in the urban area group. Therefore, the alma mater factor greatly contributed to facility selection; however, it was thought that the contribution of this factor was not as great in the provincial area group when compared with that in the urban area group.

Next, the selection of hometown was examined. According to an investigation made by the MHLW Health Policy Bureau, one reason for the selection of residency facility in their hometown was being near the parental home [10]. This can be also applied to the reason for which the prefectural students select Kagoshima University Medical and Dental Hospital as their residency facility, where those from other prefectures (hereinafter referred to as 'non-prefectural students') return to their hometowns. Previous studies have shown a trend for doctors to find employment in their hometown [19], and it can be assumed that a similar trend was shown for dentists. However, prefectural students were strongly inclined to select Kagoshima University when compared with non-prefectural students selecting their hometown. There could be two reasons for this. First, although there are 47 prefectures in Japan, there are only 19 prefectures having dental schools (with 11 prefectures having national universities); thus, there are many cases in which students have no dental school-affiliated hospital in their hometown. A medical school with a department of oral and maxillofacial surgery exists in each prefecture (in Japan, dentists can select oral and maxillofacial surgery for their initial residency training), but the number of students admitted is small (during the period from 2005 to 2013, the number of seats for dental school-affiliated hospitals was 27,999 , while the number of seats for medical schools was 2,785 [9.9\%]) [9]. The second reason is thought to be the coexistence of the 
Table 4. Multiple logistic regression analysis of background factors associated with selection of cities with a population greater than that of Kagoshima City.

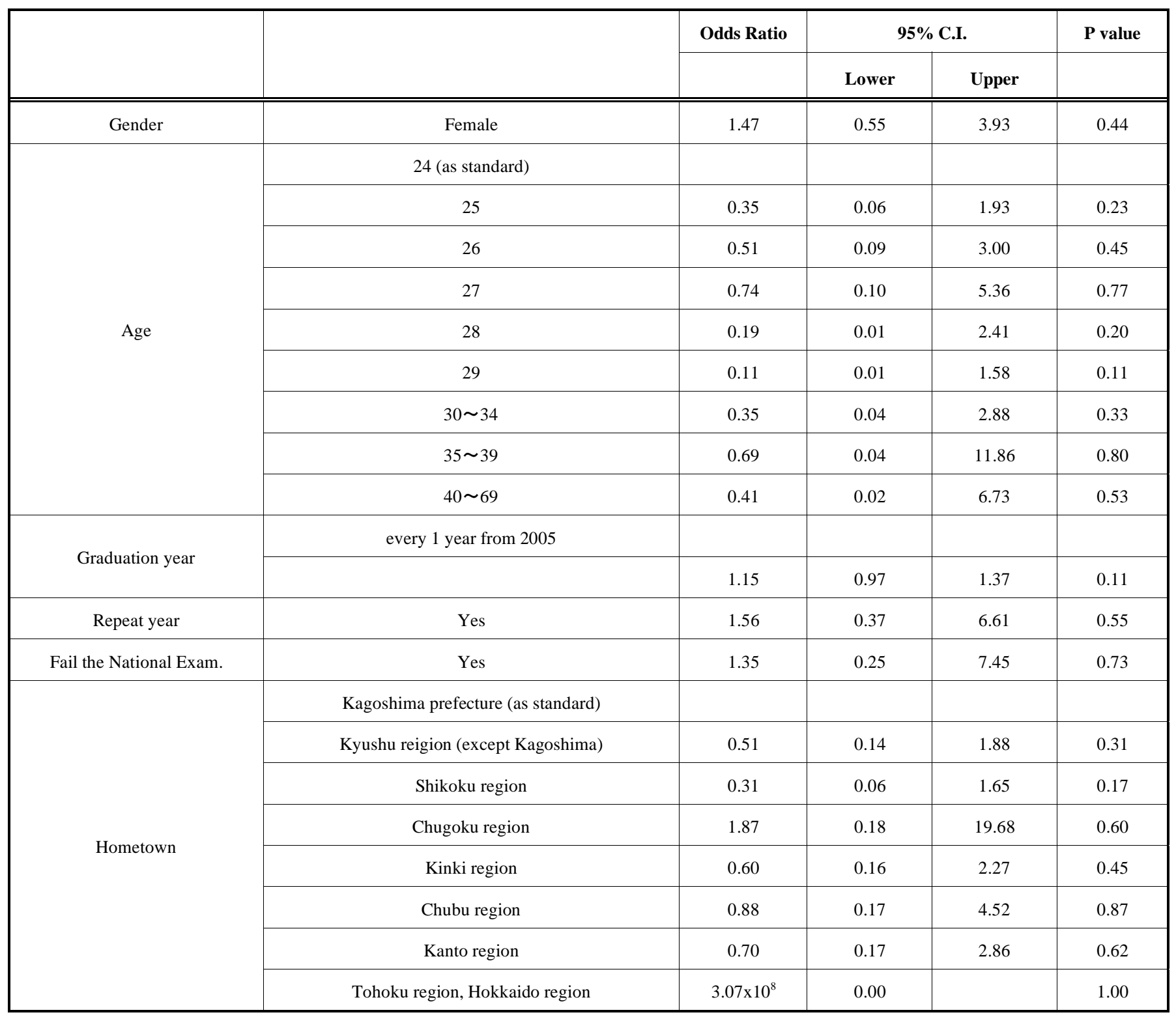

factors of hometown and alma mater as well as the fact that prefectural students selected their hometown, and nonprefectural students selected a location other than their hometown at the time of starting dental school. That is, nonprefectural students had already selected a location other than their hometown; therefore, it can be concluded that they had no reluctance in selecting another location outside their hometown. On the other hand, for prefectural students, because the obstacle of 'leaving hometown' exists, the ratio of prefectural students who selected 'alma mater' was notable. Furthermore, concerning the relationship between alma mater and repeating a school year, similar to the results of this study, another study from Akita (a provincial city located in the Tohoku region) also reported that students who had repeated a school year were significantly more likely to select the residency facility in the area in which their university was located [20]. Because the matching rate for the first choice during the period from 2005 to 2013 ranged from 70.7 to $78.0 \%$ [9], it was assumed that under the unfavourable condition of repeating a school year, the first choice could not be matched, and their last choice became their alma mater, or that they avoided popular facilities and selected the alma mater that was not meeting their quotas as their first choice. The probability of matching one of the top three choices was $94.2 \%$ during the period from 2005 to 2013 [9].

Next, an analysis of the significance of females returning to their hometown in comparison with males was performed. In an investigation of the employment of students from Japanese national universities in provincial areas, it was reported that $36.7 \%$ and $28.7 \%$ of females and males, respectively, had a preference for their hometown [21]. Furthermore, the preference for the local region to which their hometown prefecture belongs was $75.5 \%$ for females 
Table 5. Multiple logistic regression analysis of background factors associated with selection of cities with a population greater than that of the hometown area.

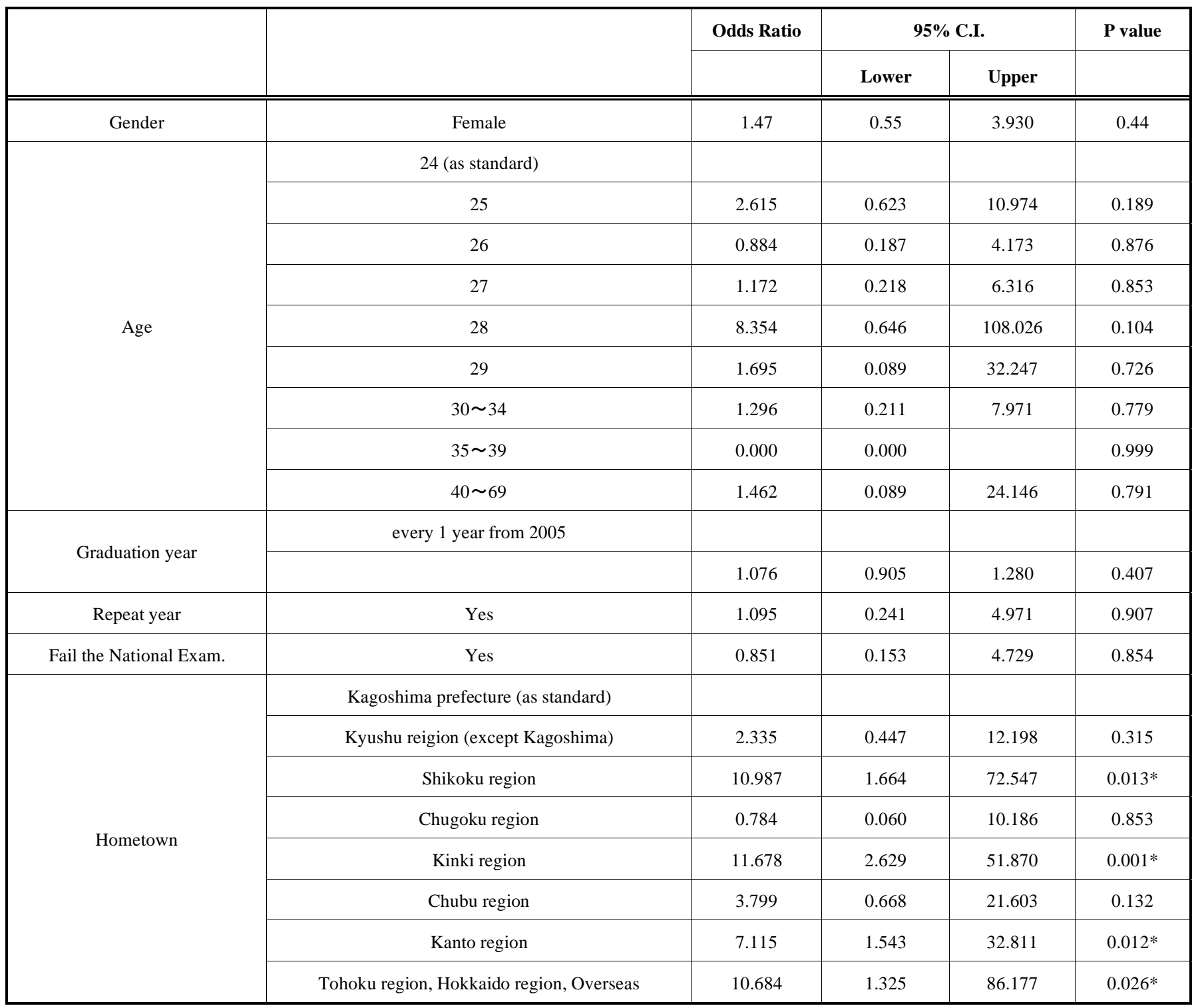

$*: \mathrm{p}<0.05$

and $64.8 \%$ for males; a strong preference for hometown was previously shown [21], and similar studies from the United States were reported [22]. Moreover, in Japan, parents hope that their children will select employment in their hometown, but in terms of gender, it has been reported that this hope is stronger for women than for men [23]. Furthermore, this hope was more prevalent in fathers than in mothers [23]; hence, the fact that fathers want their daughters to remain close by can be considered as a sociocultural factor. That is, it is assumed that the synergistic effect of the preference of female students and parents, particularly the father, led to the higher rate of women having a preference for their hometown. Concerning the selection of hometown, compared with students from Kyushu, excluding Kagoshima Prefecture, students from Kanto or Kinki regions showed a significantly lower correlation; therefore, the cause was examined. These two regions are the eastern and western centres of economic activity in Japan [24]. The regions contain many cities form- ing single economic blocs, with Tokyo as the centre of Kanto and Osaka as the centre of Kinki; both areas possess highly developed transportation networks [25]. Thus, it can be inferred that it is common for residents of these areas to work in locations differing from their place of residence; thus, the rate of students selecting residency facilities in other prefectures that are easy to commute to led to this higher rate. Therefore, it is difficult to state that the preference for the hometown of students from Kanto or Kinki was lower compared with the preference of students from other regions.

Finally, the analysis of the preference for urban areas was performed. A relationship with the preference for urban areas was observed among students from Shikoku, Kinki, Kanto, Tohoku and Hokkaido regions. Concerning Kinki and Kanto regions, there are many residency facilities located in such urban areas, but as previously mentioned in the section 


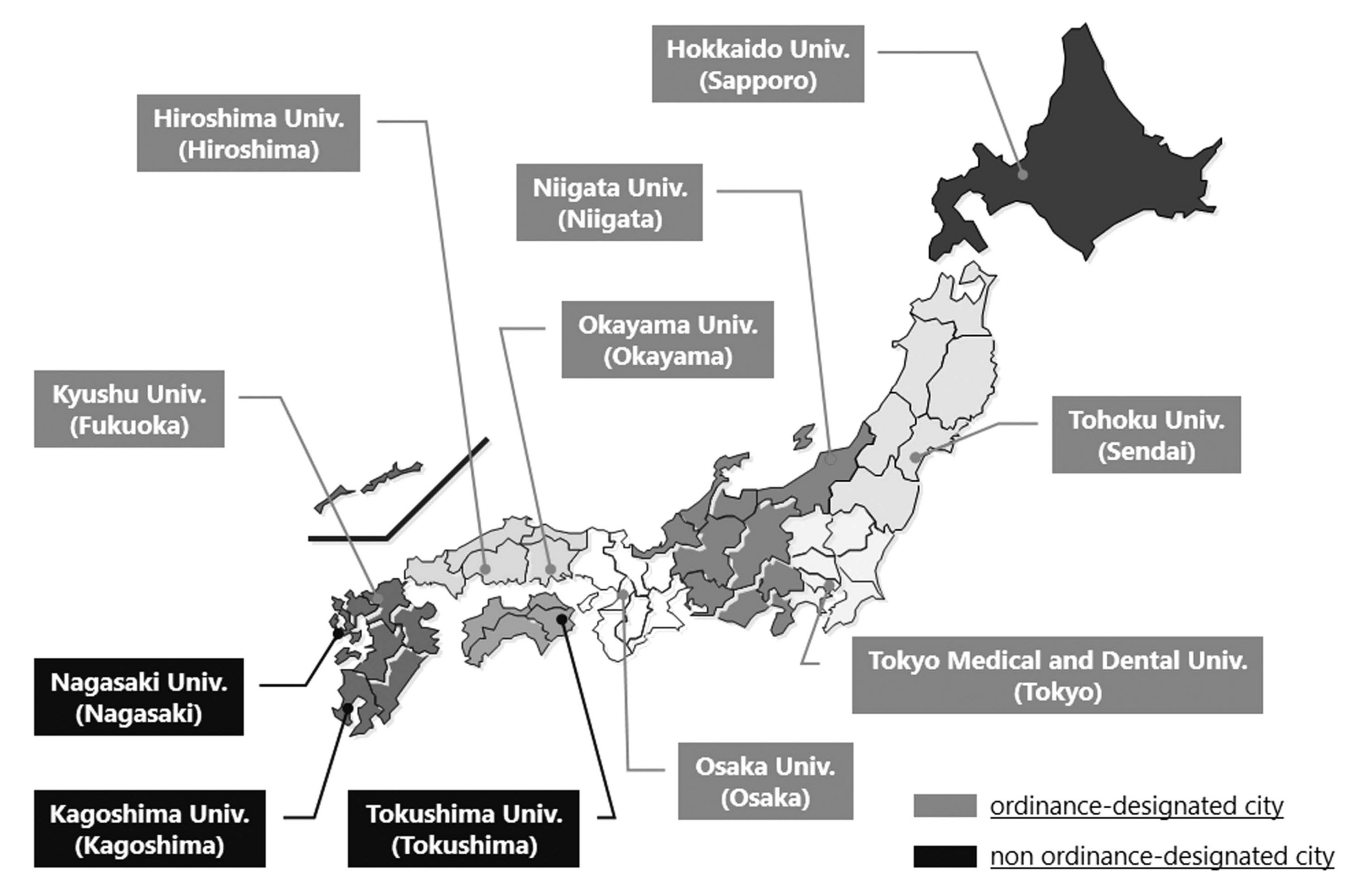

Fig. (1). Map of Japanese national universities with dental schools.

dealing with hometown, this is thought to be because of the highly developed transportation networks, and it is possible for residents to commute to work from their hometown. For example, in the case of students from the neighbouring prefectures of Tokyo in the Kanto region (Kanagawa, Chiba and Saitama Prefectures), these students have a preference for a region with their hometown prefecture but also have a preference for urban areas. The same is applicable to the Kinki region for students from Nara, Hyogo and Kyoto Prefectures with regard to commuting to Osaka. The reason for the preference for urban areas in Shikoku, Tohoku and Hokkaido is unclear, but it may be because there is only one dental school-affiliated hospital in Shikoku, and it is located in the prefectural capital of Tokushima, which has the lowest population of the four prefectures in Shikoku. In Canada, it has been reported that there is a strong association between the population of hometown and selection of work location [26]. Concerning Tohoku and Hokkaido, because the overall number of students was small, it was not possible to independently calculate their number; therefore, we could not discuss the reason for the preference for urban areas in these groups.

\section{LIMITATIONS OF THIS STUDY}

First, the results of matching may not have been the first choice of students; therefore, our analysis did not necessarily and accurately reflect the intentions of students. The mean matching rate for the first choice from 2005 to 2013 was $74.8 \%$ [9]. Second, it was highly likely that students who failed the national examination participated in matching until they passed; because the names of these students appeared multiple times in the list of students, it was possible that they influenced the results of this study. Third, because no analysis of students in universities located in government ordinance-designated cities has been performed, the difference in the behaviour of students from urban and provincial areas remains unclear. Fourth, although it has been reported that for students in a relationship, their partner was a background factor that influenced the selection of the residency facility [22], no investigation regarding the same has yet been performed.

Thus, further investigation is needed concerning the abovementioned issues pointed out in the present study.

\section{CONCLUSION}

In this study, it was clear that the hometown was an extremely strong factor in the selection of residency facilities by dental students in national universities located in provincial areas. It was reported that in Japan, in the field of medicine, a high ratio of resident doctors who underwent residency training in urban areas remained in those areas after the end of their residency training [6]. However, students undergoing residency training in provincial areas and continuing clinical practice in the same areas were also reported [27]. Unlike medical departments, national or prefectural departments of dentistry are not in each prefecture in Japan [9], which has led to an imbalance in quotas for local students at the prefectural level. Therefore, it is difficult to establish quotas. However, among those who had a preference for their hometown, there were some who had a preference for their home prefecture, while others had a preference for a region with their home prefecture, and as already shown, both male and female students of national universities in rural areas had a high preference for a region with their home prefecture [21]. Thus, the establishment of local quotas (such as a quota for students from Southern Kyushu) in national universities located in provincial areas, where possible, is one of the most effective policies. The establishment of deliberate policies to ensure the appropriate number of students and dental trainees who will support dental healthcare in the local community in the future is essential. It is the authors' opinion that in future studies, it will be necessary to examine 
the selection of employment location by dentists who have completed their residency training.

\section{CONFLICT OF INTEREST}

The authors confirm that this article content has no conflict of interest.

\section{ACKNOWLEDGEMENTS}

This research was partially supported by Japan Society for the Promotion of Science (JSPS) KAKENHI, Grant-inAid for Scientific Research (C), Grant Number 25463255.

\section{REFERENCES}

[1] Taguchi N, Ogawa T, Sasahara H. Japanese dental trainees' perceptions of educational environment in postgraduate training. Med Teach 2008; 30(7): e189-93.

[2] Taguchi N, Ogawa T. OSCEs in Japanese postgraduate clinical training Hiroshima experience 2000-2009. Eur J Dent Educ 2010; 14(4): 203-9.

[3] Gale D, Shapley LS. College admissions and the stability of marriage. Am Mathemat Monthly 1962; 69(1): 9-15.

[4] Onishi H, Yoshida I. Rapid change in Japanese medical education. Med Teach 2004; 26(5): 403-8.

[5] Teo A. The current state of medical education in Japan: a system under reform. Med Educ 2007; 41(3): 302-8.

[6] Health Policy Bureau, Ministry of Health Labour and Welfare. Committee report concerning the current state of medical specialists 2013. http://www.mhlw.go.jp/stf/shingi/2r985200000300juatt/2r985200000300lb.pdf [Accessed 9 September 2014].

[7] Hirata S, Mataki S, Akiyama H, et al. Geographic distribution of postgraduate dental trainees in Japan. Bull Tokyo Dent Coll 2009; 50(2): 63-70.

[8] Ministry of Health and Welfare. Committee report concerning supply and demand of dentists http://www1.mhlw.go.jp/houdou/ 1005/h0529-1.html [Accessed 9 September 2014].

[9] Foundation for Promotion of Dental Training. Japanese residency match programme. Available from: https://www.drmp.jp/data.shtml [Accessed 9 September 2014].

[10] Foundation for Promotion of Medical Training. Japanese Residency Match Programme. Available from: http://www.jrmp.jp/ data.html [Accessed 9 September 2014].

[11] Kruger E, Tennant M. Short-stay rural and remote placements in dental education, an effective model for rural exposure: A review of eight-year experience in Western Australia. Aust J Rural Health 2010; 18(4): 148-52.
[12] Spencer AJ, Teusner DN, Carter KD, Brennan DS. The dental labour force in Australia: The position and policy directions. Popul Oral Health Series, no. 2, 2003.

[13] Johnson G, Blinkhorn A. The influence of a clinical rural placement programme on the work location of new dental graduates from the University of Sydney, NSW, Australia. Eur J Dent Educ 2013; 17(4): 229-35

[14] Guay AH. Access to dental care - Solving the problem for underserved populations. J Am Dent Assoc 2004; 135(11): 1599-605.

[15] Skillman SM, Doescher MP, Mouradian WE, Brunson DK. The challenge to delivering oral health services in rural America. J Public Health Dent 2010; 70: S49-S57.

[16] Smith RG. Bridging the rural-urban divide. J Can Dent Assoc 2010; 76: a97.

[17] Okawa Y, Hirata S, Okada M, Ishii T. Geographic distribution of dentists in Japan: 1980-2000. J Public Health Dent 2011; 71(3): 236-40.

[18] Lin HL, Rowland ML, Fields HW. In-state graduate retention for U.S. dental schools. J Dent Educ 2006; 70(12): 1320-7.

[19] Laven G, Wilkinson D. Rural doctors and rural backgrounds: how strong is the evidence? A systematic review. Aust J Rural Health 2003; 11(6): 277-84.

[20] Minamizono S, Hasegawa H, Hasunuma N, Kaneko Y, Motohashi Y. Career path trends of graduates of Akita University Faculty of Medicine - from the start of the new residency system. Akita J Public Health 2010; 8(1): 26-30.

[21] Hiramatsu M, Shigematsu M. Local area preference and attitudes concerning employment of university students. J High Edu 2006; 3 : 161-8.

[22] Saeed S, Jimenez M, Howell H, Karimbux N, Sukotjo C. Which factors influence students' selection of advanced graduate programs? One institution's experience. J Dent Edu 2008; 72(6): 6889.

[23] Hiramatsu M. Opinions of parents regarding the university students' job searching -a questionnaire survery of parents of third year students at Yamaguchi University. J High Edu 2006; 1: 10313.

[24] Donald R, Davis DEW. Market size, linkages, and productivity: a study of japanese regions. NBER Working Paper 2001; (No. 8518): $1-28$.

[25] Murayama Y. The impact of railways on accessibility in the Japanese urban system. J Transp Geog 1994; 2(2): 87-100.

[26] Easterbrook M, Godwin M, Wilson R, et al. Rural background and clinical rural rotations during medical training: effect on practice location. CMAJ 1999; 160(8): 1159-63.

[27] Matsumoto M, Okayama M, Inoue K, Kajii E. Factors associated with rural doctors' intention to continue a rural career: a survey of 3072 doctors in Japan. Aust J Rural Health 2005; 13(4): 219-25.

Received: December 07, 2014

Revised: March 26, 2015

Accepted: March 27, 2015

(C) Kono et al.; Licensee Bentham Open.

This is an open access article licensed under the terms of the Creative Commons Attribution Non-Commercial License (http://creativecommons.org/licenses/by-nc/3.0/) which permits unrestricted, non-commercial use, distribution and reproduction in any medium, provided the work is properly cited. 